\title{
Venus Figurines of the European Paleolithic: Symbols of Fertility or Attractiveness?
}

\author{
Alan F. Dixson and Barnaby J. Dixson \\ School of Biological Sciences, Victoria University of Wellington, Wellington 6140, New Zealand \\ Correspondence should be addressed to Alan F. Dixson, alan.dixson@vuw.ac.nz
}

Received 8 July 2011; Accepted 4 November 2011

Academic Editor: Benjamin Campbell

Copyright ( $) 2011$ A. F. Dixson and B. J. Dixson. This is an open access article distributed under the Creative Commons Attribution License, which permits unrestricted use, distribution, and reproduction in any medium, provided the original work is properly cited.

\begin{abstract}
The earliest known representations of the human female form are the European Paleolithic "Venus figurines," ranging in age from 23,000 to 25,000 years. We asked participants to rate images of Paleolithic figurines for their attractiveness, age grouping and reproductive status. Attractiveness was positively correlated with measures of the waist-to hip ratio (WHR) of figurines, consistent with the "sexually attractive symbolism" hypothesis. However, most figurines had high WHRs $(>1.0)$ and received low attractiveness scores. Participants rated most figurines as representing middle-aged or young adult women, rather than being adolescent or older (postmenopausal). While some were considered to represent pregnant women, consistent with the "fertility symbol" hypothesis, most were judged as being non-pregnant. Some figurines depict obese, large-breasted women, who are in their mature reproductive years and usually regarded as being of lower attractiveness. At the time these figurines were made, Europe was in the grip of a severe ice age. Obesity and survival into middle age after multiple pregnancies may have been rare in the European Upper Paleolithic. We suggest that depictions of corpulent, middle-aged females were not "Venuses" in any conventional sense. They may, instead, have symbolized the hope for survival and longevity, within well-nourished and reproductively successful communities.
\end{abstract}

\section{Introduction}

The oldest known representations of the human female form are the so-called "Venus figurines" of the upper Paleolithic period. Venus figurines have been unearthed at multiple sites across Europe, and most have been dated between 23,000 and $25,000$ years ago [ $1-3]$. Most recently a figurine, thought to be 35,000 years old, has been recovered from the Hohle Fels Cave in Germany [4]. The majority of Venus figurines are relatively small, portable objects (e.g., Hohle Fels Venus: $6 \mathrm{~cm}$ high; Willendorf's Venus: $11 \mathrm{cms}$ high). They were made from a variety of materials (e.g., limestone: the Willendorf Venus; ivory: the Kostenki figurines; clay and bone, fired at high temperature: the Dolní Věstonice Venus). However, in a few cases they take the form of bass-relief carvings on rock surfaces (e.g., the Laussel Venus).

The name commonly applied to these objects, "Venus figurines", carries with it the implication that they were made as representations of feminine beauty. However, a considerable diversity of opinion exists in the archeological and paleoanthropological literature regarding the possible functions and significance of these objects. Delporte [1], for example, listed five possible areas for interpretation of Venus figurines. He noted that (1) the statuettes might be realistic depictions of actual women, (2) they might be ideal representations of female beauty, (3) they could represent fertility symbols, (4) they might have religious significance and be depictions of priestesses, and (5) they could represent images of ancestors. Some have suggested that figurines also constitute evidence of the occurrence of obesity in Paleolithic times, given that the majority are depictions of corpulent women [5]. Russell [6] points out that some of the variability in these figurines may reflect the individual styles and preferences of those who crafted the objects and that styles may have changed throughout time. She draws some interesting parallels between paleolithic art and stylistic changes in modern artistic representations of the female form. It is widely thought that Venus figurines were made by men. However, some have challenged this assumption including McDermott [7] who proposed that Venus figurines 
were crafted by women, who were making images of their own bodies, rather than using other women as models.

Despite differences of opinion regarding the functions and significance of Venus figurines, relatively few attempts have been made to measure how people might interpret their attractiveness, reproductive status (e.g., pregnant or nonpregnant), and whether they depict women who are young, middle-aged, or in their postreproductive years. Rice [8] conducted one such study, using 188 figurines, which she rated (along with four experienced colleagues) for age and reproductive status. Rice concluded that various figurines represented different stages in the life span of women at that time and attempted to relate the results to observations of the physique of modern day hunter-gatherer women. However, many Paleolithic figurines depict women who are very heavily built, with greatly exaggerated breasts and buttocks, quite unlike those of modern hunter-gatherers. By contrast, some other figurines are much slimmer and more lifelike in their proportions (see Figure 1, e.g., of these various types). The problem in using small numbers of trained observers, as in Rice's study, is that they are likely to have preconceptions about the significance of the statuettes. It remains to be determined how larger numbers of untrained participants might interpret Venus figurines.

Studies of more recent archeological material have addressed the question of whether female figurines might be representations of the sexually attractive female form. Singh [9] measured waist-to-hip ratios (WHR) in statuettes from ancient Egypt, India and Africa. Singh showed that a low female WHR, such as is judged as highly sexually attractive in many modern populations, was typical of these ancient statuettes. Likewise, Hudson and Aoyama [10] found that Jomon clay figurines made in Japan, made by hunter-gatherers between 16,500-2,500 years ago, typically depict females with low WHRs. These authors conclude that "in creating these figurines, prehistoric people were no doubt turning a recognition of health and fertility into more cultural icons."

In the current study, we have used two approaches to examine the possible significance of Paleolithic Venus figurines. Firstly, we selected images of female figurines originating from a variety of European sites. We then designed a questionnaire that incorporated these images, in order to collect quantitative data on their perceived sexual attractiveness, age, and pregnancy status. Secondly, we asked participants to view Venus figurines via an eye-tracking machine, in order to measure visual attention to specific morphological features during attractiveness judgments. The goal of the first study was to obtain quantitative information on how figurines originating from different parts of Europe might vary, in terms of their perceived attractiveness and reproductive status. The second study sought to determine whether men who view such statuettes exhibit similar patterns of visual attention to those measured in previous studies, using images of modern-day women [11].

\section{Method}

2.1. Participants. In study 1,161 heterosexual men and women, ranging in age from 18 to 58 ( $M=20.68$ years;
$\mathrm{SD}=5.12$ ) who were undergraduate students at the Victoria University of Wellington, were asked to view a questionnaire consisting of 14 images of Paleolithic Venus figurines, originating from various parts of Europe (as detailed below) and a single modern sculpture.

In study 2, 35 heterosexual men, ranging in age from 23 to 44 years $(\mathrm{M}=29.34$ years; $\mathrm{S} . \mathrm{D}=5.472)$ were recruited opportunistically from the postgraduates and staff at Victoria University of Wellington, completed eye-tracking experiments in which they viewed images of Venus figurines and a modern woman (as detailed below).

For both studies, participants were given verbal orientation before the start of data collection. The details of the study were not discussed with participants beforehand. However, when the studies ended, participants were provided with details of the rationale of the research. Participation was voluntary and anonymous. Participants were told of their right to withdraw themselves or their data from the study without prejudice.

\subsection{Study 1: Questionnaire}

2.2.1. Stimuli. We selected of subset of Venus figurines consisting of images of 14 Venus figurines and a single modern sculpture of a female body. These images are shown in Figure 1. All images were front-posed and corrected to be approximately the same height. The images were presented in random order and numbered, as shown in Figure 1. The figurines chosen for this study are from five European regions, defined by [1] as follows: The Rhine/Danube (Image 1, 4, 6, and 10), The Pyrenees/Aquitaine (Image 2, 3, and 14), Italy (Image 8, 9, and 13), Russia (5, 7, and 12), and SW Germany (Image 15). The image depicting a modern sculpture (Image 11) was scanned from http://www.borsheimarts.com.

2.2.2. Procedure. Each image was presented individually and in a random sequence. Participants viewed each image for 15 seconds, during which they were asked to provide ratings of age, pregnancy status, and attractiveness.

2.2.3. Measures. Participants classified each image as depicting a woman belonging to one of four age groups: "adolescent" (post-pubertal but not yet fully adult), "young adult" (in the prime reproductive years), "middle aged" (past prime, but not menopausal), and "old age" (after menopause). Participants were not asked to assess the exact age, in years, of women depicted by the statuettes nor were they told what age range might constitute adolescence, young adulthood, middle age, and old age. This was because the processes of adolescence and aging in adulthood may have occurred at different rates among hunter-gathers in the Paleolithic than is the case in modern, industrialized, human populations. Participants were also asked to judge whether each figurine might represent either a pregnant or a nonpregnant woman. Attractiveness of each image was rated using a six-point Likert's scale in which $0=$ unattractive, $1=$ only slightly attractive, 2 = mildly attractive, 3 = moderately attractive, 4 = very attractive, $5=$ extremely attractive. 

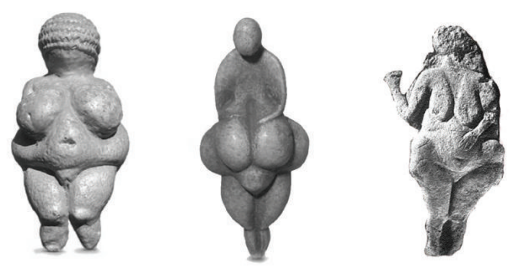

3
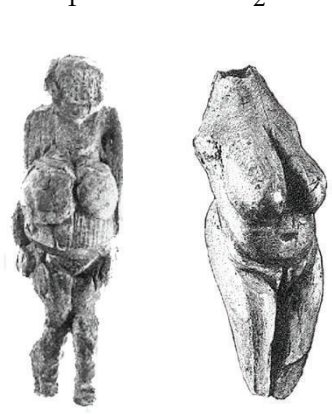

6

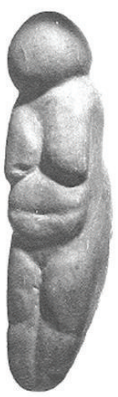

9

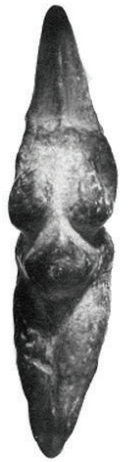

13

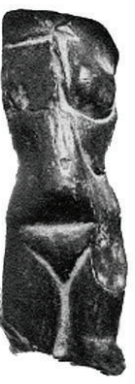

10

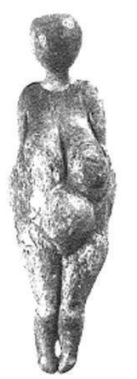

7

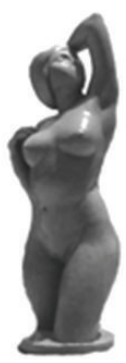

11

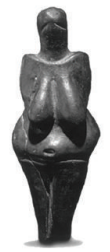

4

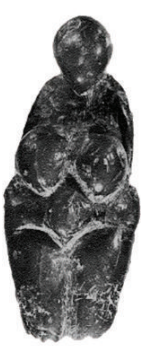

8

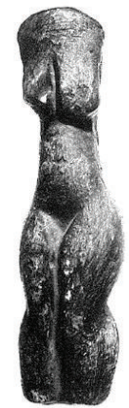

12

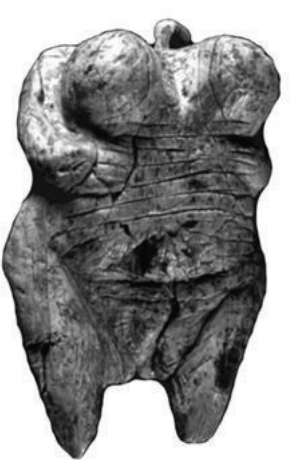

15

FIGURE 1: Images of figurines and their geographic origins. Images are shown in the same (random) order and numbered, as they were for the questionnaire study. (1) Willendorf's Venus (Rhine/Danube), (2) Lespugue Venus (Pyrenees/Aquitaine), (3) Laussel Venus (Pyrenees/Aquitaine), (4) Dolní Věstonice Venus (Rhine/Danube), (5) Gagarino no. 4 Venus (Russia), (6) Moravany Venus (Rhine/Danube), (7) Kostenki 1. Statuette no. 3 (Russia), (8) Grimaldi nVenus (Italy), (9) Chiozza di Scandiano Venus (Italy), (10) Petrkovice Venus (Rhine/Danube), (11) Modern sculpture (N. America), (12) Eleesivitchi Venus (Russia); (13) Savignano Venus (Italy), (14) The so-called "Brassempouy Venus" (Pyrenees/Aquitaine), (15) Hohle Fels Venus (SW Germany). 
The same Likert scale has been used in previous studies of female WHR and attractiveness [11].

\subsection{Study 2: Eye Tracking}

2.3.1. Stimuli. Two images of Venus figurines were used for the eye-tracking study: image no. 1 of the Willendorf Venus, and image no. 14 of the so-called "Brassempouy Venus." These figurines are examples of somewhat more (Image 14) or less (Image 1) "hourglass-shaped" body types. Image no. 14 also includes more modeling of facial features than in most other Venus figurines, and we wished to determine how this might affect eye-tracking responses. However, this figurine (referred to as no. 14 throughout this report) is highly problematic due to debates concerning the accuracy of its reconstruction $[12,13]$. This matter is considered in the Discussion section. Data referring to the eye movements on the Venus figurines were compared to those made on a photograph of a modern woman used in a previous study [11].

The experiment was programmed using SR Research Experiment Builder (version 1.4.128 RC) and run on a $3-\mathrm{GHz}$ Pentium D computer. Stimuli were presented on a 21inch monitor at a resolution of $1024 \times 768$ pixels and with a refresh rate of $60 \mathrm{~Hz}$.

2.3.2. Procedure. Participants were seated in a comfortable chair in a quiet room facing the monitor at eye level at a viewing distance of $57 \mathrm{~cm}$, maintained by a forehead and chin rest. They underwent eye-tracking trials in which each image was presented individually, in random order on the computer screen for five seconds.

\subsubsection{Measures}

Attractiveness. At the end of each presentation, participants were instructed to rate the image for sexual attractiveness using a keyboard with a six-point Likert's scale in which $0=$ unattractive, $1=$ somewhat attractive, $2=$ moderately attractive, $3=$ attractive, $4=$ very attractive, and $5=$ extremely attractive.

Eye Tracking. Using the EyeLink 1000 Tower Mount Head Supported System (SR Research Ltd., ON, Canada), eye position and eye movements were determined by measuring the corneal reflection and dark pupil with a video-based infrared camera and an infrared reflective mirror. The eye tracker had a spatial resolution of $0.01^{\circ}$ of visual angle, and the signal was sampled and stored at a rate of $1000 \mathrm{~Hz}$. While viewing was binocular, recording was monocular, measuring right-eye movements only as this is a standard procedure in eye-tracking studies (e.g., [14]). Calibration and validation of measurements were performed before each experimental session.

The stimulus images were divided into six anatomical regions for subsequent analysis of eye-tracking data. The six regions were defined as follows: (1) the face and neck, from the top of the head to the base of the neck; (2) breasts, from

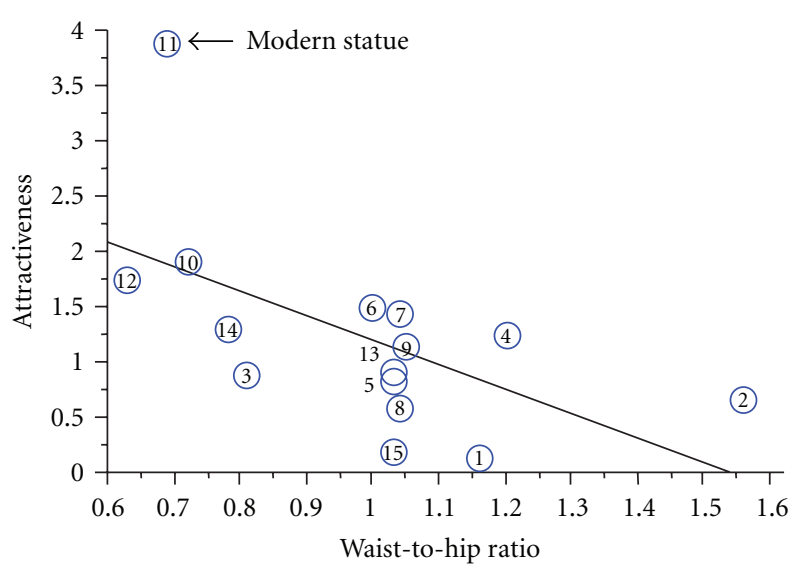

FIGURE 2: Scatter plot with regression showing the negative relationship between waist-to-hip ratio and the mean attractiveness ratings for all the 15 images, $\left(R^{2}=.34,95 \%\right.$ CI $(-3.41,-2.21)$. After removing image 11 of the modern statue the regression was $\left(R^{2}=.31,95 \%\right.$ CI $(1.255,-.24)$. Images are numbered as in Figure 1.

the base of the neck to the posterior border of each breast; (3) midriff, including the waist beginning from the below the breasts to the widest part of the hips; (4) pubis, as defined by the limits of the pubic triangle; (5) the thighs, the upper portion of the leg ending at the knee; (6) lower legs and feet.

In each of the six regions, two dependent variables of eye movement were measured: number of fixations and amount of time spent (dwell time) examining the area. Each time the eye moved, the eye-tracking machine recorded a new fixation. Total fixations that occurred in each area were summed during the analysis. Likewise, the machine measured individual fixation times, so that it was possible to obtain the total time spent examining each of the six regions.

\section{Results}

\subsection{Study 1: Questionnaire Study}

3.1.1. Waist-to Hip Ratios and Attractiveness. Table 1 presents data on attractiveness ratings, waist-to hip ratios (WHR), perceived age, and pregnancy status for the individual images shown in Figure 1. There was a negative relationship between WHR and attractiveness judgments for the 15 images $\left(R^{2}=.34,95 \%\right.$ CI $(-3.41,-2.21)$; Figure 2$)$, which remained when removing the data from the modern statue and retaining only the data from the 14 Venus figurines $\left(R^{2}=.31,95 \%\right.$ CI $(1.255,-.24)$. Those images ranked as having the lowest WHRs were accorded the highest rankings for attractiveness (Spearman's rank correlation coefficient $=0.66 ; P<.02)$. Image no. 11, depicting a modern sculpture of a young woman which had a WHR of 0.69 , received the highest score for attractiveness (3.89). Images 10 and 12, which had low WHRs, were accorded the highest average ratings for attractiveness among the Paleolithic figurines (no. 10 Petrkovice: attractiveness 1.92, WHR 0.72 ; no. 12 Eleesivitchi: attractiveness 1.74 , WHR 0.63 ). Those figurines having high WHRs received much lower 
TABLE 1: Waist-to hip ratio (WHR), mean attractiveness rating, and numbers of participants rating the images (shown in Figure 1) as being pregnant or nonpregnant and belonging to one of four age groups.

\begin{tabular}{|c|c|c|c|c|c|c|c|c|c|}
\hline \multirow{2}{*}{ Image number and name } & \multirow{2}{*}{ WHR } & \multirow{2}{*}{$\begin{array}{l}\text { Attractiveness } \\
\text { rating }\end{array}$} & \multicolumn{2}{|c|}{ Pregnant? } & \multirow{2}{*}{ Adolescent? } & \multirow{2}{*}{$\begin{array}{l}\text { Young } \\
\text { adult? }\end{array}$} & \multirow{2}{*}{$\begin{array}{l}\text { Middle } \\
\text { aged? }\end{array}$} & \multirow{2}{*}{ Old? } & \multirow{2}{*}{$\begin{array}{l}\text { no. of } \\
\text { participants }\end{array}$} \\
\hline & & & Yes & No & & & & & \\
\hline (1) Willendorf & 1.16 & 0.14 & 34 & $127^{* * *}$ & 1 & 7 & $122^{* * *}$ & 31 & 161 \\
\hline (2) Lespugue & 1.56 & 0.66 & 70 & 91 & 5 & $71^{* * *}$ & $71^{* * *}$ & 14 & 161 \\
\hline (3) Laussel & 0.81 & 0.90 & $125^{* * *}$ & 36 & 3 & 57 & $86^{* * *}$ & 15 & 161 \\
\hline (4) Dolní Věstonice & 1.20 & 1.25 & 91 & 70 & 6 & $69^{* * *}$ & $83^{* * *}$ & 3 & 161 \\
\hline (5) Gagarino & 1.03 & 0.83 & 89 & 72 & 14 & 54 & 44 & 49 & 161 \\
\hline (6) Moravany & 1.00 & 1.50 & 83 & 78 & 1 & $67^{* * *}$ & $88^{* * *}$ & 5 & 161 \\
\hline (7) Kostenki & 1.04 & 1.44 & $148^{* * *}$ & 13 & 35 & $82^{* * *}$ & 37 & 7 & 161 \\
\hline (8) Grimaldi & 1.04 & 0.61 & 36 & $125^{* * *}$ & 1 & 24 & $94^{* * *}$ & 42 & 161 \\
\hline (9) Chiozza di Scandiano & 1.05 & 1.11 & 76 & 85 & $60^{*}$ & $64^{* *}$ & 32 & 5 & 161 \\
\hline (10) Petřkovice & 0.72 & 1.92 & 12 & $149^{* * *}$ & 40 & $97 * * *$ & 18 & 6 & 161 \\
\hline (11) Modern Statue & 0.69 & 3.89 & 0 & $161^{* * *}$ & 2 & $151^{* * *}$ & 8 & 0 & 161 \\
\hline (12) Eleesivitchi & 0.63 & 1.74 & 7 & $154^{* * *}$ & 17 & $99 * * *$ & 44 & 1 & 161 \\
\hline (13) Savignano & 1.03 & 0.92 & $141^{* * *}$ & 20 & 4 & 36 & $103^{* * *}$ & 18 & 161 \\
\hline (14) Brassempouy & 0.78 & 1.30 & 75 & 86 & 1 & 22 & $126^{* * *}$ & 12 & 161 \\
\hline (15) Hohle Fels & 1.03 & 0.19 & 26 & $90^{* * *}$ & 1 & 8 & 40 & $67 * * *$ & 116 \\
\hline
\end{tabular}

Chi-squared: ${ }^{*} P<.05 ;{ }^{* *} P<.01 ;{ }^{* * *} P<.001$. Where observed numbers of participants selecting a particular category exceeded those expected to do so at chance levels.

scores for attractiveness. Examples include the Willendorf Venus (attractiveness 0.14, WHR 1.16), the Lespugue Venus (attractiveness 0.66 , WHR 1.56), and the recently discovered Hohle Fels Venus (attractiveness 0.19, WHR 1.03). These, and other figurines, were given ratings averaging less than 1 and were thus perceived as being "unattractive."

Nine of the 14 Paleolithic figurines had high WHRs (i.e., 1.0 or higher), with greatly accentuated breasts and generally "squat" or obese body shapes. These types of figurines are widely represented at sites across Europe (e.g., in Figure 1: Rhine Danube: the Willendorf and Dolní Věstonice figurines; Italy: the Grimaldi Venus; Pyrenees/Aquitaine: the Lespugue Venus; Russia: the Gagarino no. 4 figurine). Figurines with slimmer waists are less well represented, but examples included in this study, having low WHRs, also originate from some of these same geographical regions (e.g., Rhine/Danube: the Petrkovice figurine, Russia: Eleesivitchi figurine, and from the Pyrenees/Aquitaine: image no. 14, which has a WHR of 0.78).

3.1.2. Age Groupings, Pregnancy Status, and Attractiveness. Overall, the Paleolithic figurines were rated by significant numbers of subjects as being representations of middleaged or young adult women. Considering all of the Venus figurines, significantly higher percentages of subjects placed them in the "young adult" and "middle-aged" categories than in the "adolescent" category $(P<.01$ for each paired comparison, Wilcoxon's signed-ranks tests: see Figure 3). Subjects were also much more likely to interpret figurines as being depictions of "middle-aged" than of "old" women $(P<.01)$ and were slightly more likely to place them in the "young adult" rather than in the "old" category $(P<.05$, Figure 3). Considering scores for the individual images, most subjects placed the Willendorf, Laussel, Grimaldi, Savignano and figurines, and the problematic Brassempouy example, in the "middle-aged" category, and the Kostenki, Chiozza di Scandiano, Petrkovice, and Eleesivitchi Venuses in the "young adult" age category (Table 1). As expected, the image depicting a modern sculpture of a young woman was also rated as being a "young adult" by the great majority (94\%) of subjects. Mann-Whitney $U$ tests showed that ratings for attractiveness in the "young adult" category $(\mathrm{M} \pm \mathrm{SEM}=2.02$ \pm 0.49 ) were significantly greater than the scores given to the 5 "middle-aged" Venuses $(0.77 \pm 0.19 ; U=1 ; n 1=5, n 2$ $=5 ; P<.05)$. Figurines rated as being "young adults" also had lower WHRs, on average, $(0.83 \pm 0.09)$ than those in the "middle-aged" group $(0.96 \pm 0.07)$. However, this difference was not statistically significant $(U=7.5 ; n 1=5, n 2=5$; $P>.05)$.

Only one figurine was interpreted as representing an old (postmenopausal) woman; thus, most subjects (67 out of 116 (58\%); $P<.001)$ placed the Hohle Fels Venus, from SW Germany in this age category. Forty subjects (34\%) rated this figurine as "middle-aged," but this was not statistically significant. Likewise, only one figurine was rated as possibly representing an "adolescent" female: this was the Chiozza Di Scandiano Venus, which was also rated as a "young adult" by significant numbers of subjects (Table 1). Two figurines (Lespugue and Moravany) were judged by similar numbers of subjects to represent either young adult or middle-aged women. Only one figurine (the Gagarino no. 4 Venus) failed to receive significant ratings in any of the adult age categories, as similar numbers of subjects rated it as representing a young adult, a middle-aged, or an old woman.

Three of the 15 images were judged by significant numbers of subjects as being depictions of pregnant women 


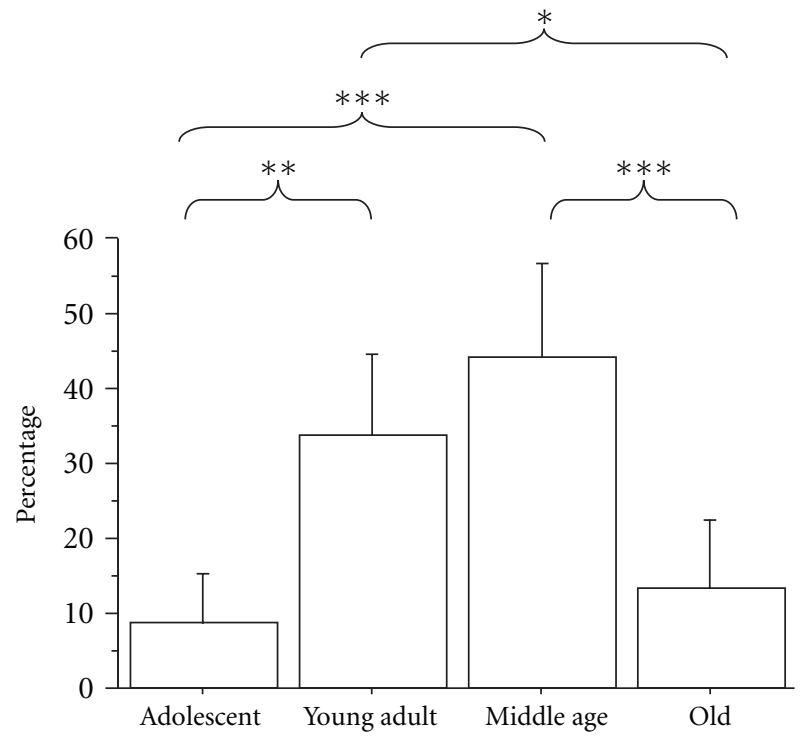

FIGURE 3: Age-group ratings (mean percentages \pm SEM) for the 14 Paleolithic figurines. Participants were significantly more likely to rate images as being representations of "middle-aged" or "young adult" women. Wilcoxon signed-ranks test: ${ }^{*} P<.05$; ${ }^{* *} P<.01$; *** $P<.001$.

(Laussel, Kostenki, and Savignano), while 5 others were thought to be nonpregnant (Willendorf, Grimaldi, Petrkovice, Eleesivitchi, and Hohle Fels). The image representing a modern sculpture of a young woman was likewise judged to be nonpregnant. In the remaining 5 cases, similar numbers of subjects considered that the figurines represent either nonpregnant or pregnant women, so that the results were not statistically significant (Table 1).

\subsection{Study 2: Eye-Tracking Study}

3.2.1. Attractiveness. A single factor (image 14, Willendorf's Venus, modern image) repeated measures analysis of variance (ANOVA) yielded a significant main effect for attractiveness $F(2,68)=115.04, P<.001$. Post-hoc Scheffé's tests revealed that the modern image was judged to be significantly more attractive than image 14 and the Venus of Willendorf $(P<.001)$. Figurine no. 14 was rated as being significantly more attractive than the Willendorf Venus $(P<$ .01 ; Figure 4).

\subsubsection{Numbers of Fixations and Dwell Times. A 3 (Image)} $\times 6$ (Body Region) repeated measures ANOVA yielded a significant main effect of image $\times$ body region, for numbers of fixations $F(10,340)=12.04, P<.001$ and dwell times $F(10,340)=17.94, P<.001$. Most visual attention involved the breasts, faces, and midriffs of all three images, with less numbers of fixations and shorter dwell times for the lower body. Considering the upper body first, when compared to the modern image, the breasts of the Willendorf Venus received significantly more fixations, $t(34)=4.90, P<.001$, and longer dwell times, $t(34)=5.82, P<.001$. Figurine no. 14 also received more visual attention on the breasts than the
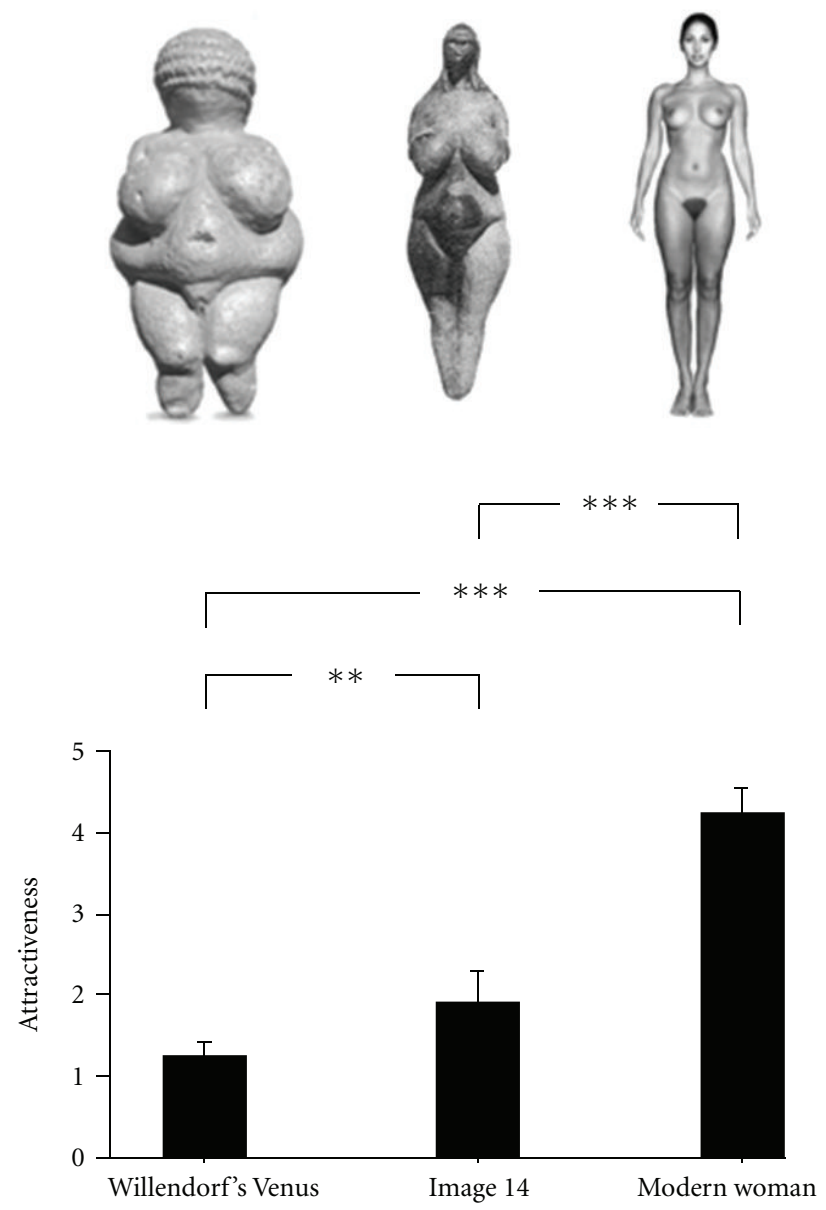

FIgURE 4: Attractiveness ratings, made by men who viewed the Willendorf Venus; Image 14: the so-called "Brassempouy Venus," and the image of a modern woman, during eye-tracking sessions. Scheffé tests: ${ }^{* *} P<.01 ;{ }^{* * *} P<.001$.

modern image (numbers of fixations: $t(34)=3.48, P<.001$, and dwell times: $t(34)=2.02, P=.052)$. Visual attention toward the breasts of the Willendorf Venus was significantly higher than figurine no. 14 for both numbers of fixations, $t(34)=2.48, P<.05$, and dwell times, $t(34)=4.34, P<.001$ (Figure 5). Attention toward the midriff of figurine no. 14 was significantly greater than the modern image for both numbers of fixations, $t(34)=2.65, P<.05$, and dwell times, $t(34)=6.99, P<.001$. Dwell times were also greater on the midriff of figurine no. 14 compared to the Willendorf Venus, $t(34)=5.79, P<.001$ (Figure 5). The face of the modern woman attracted more fixations, $t(34)=2.43, P<.05$, and longer dwell times, $t(34)=5.24, P<001$, than figurine no. 14. Similarly, the face of the modern woman was looked at more frequently than that of the Willendorf figurine, $t(34)=$ $2.90, P<.01$.

Turning to the lower body, the pubic region of the modern woman received more attention as compared to the Willendorf Venus (numbers of fixations: $t(34)=2.96, P<.01$, and dwell times: $t(34)=3.37, P<.01)$. The pubis of figurine no. 14 attracted more fixations, $t(34)=2.72, P<.01$, and greater dwell times, $t(34)=3.86, P<.001$, compared to the 


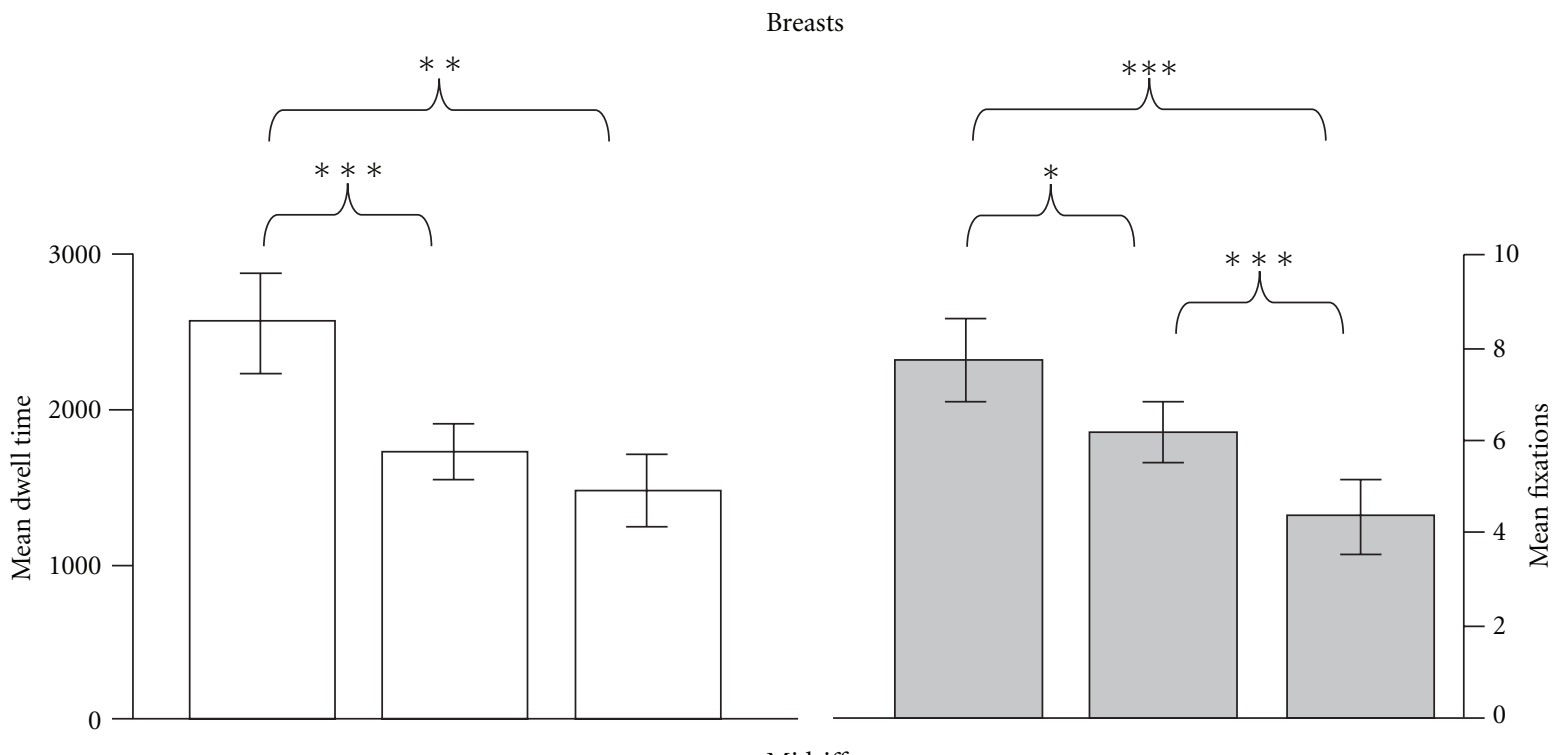

Midriff
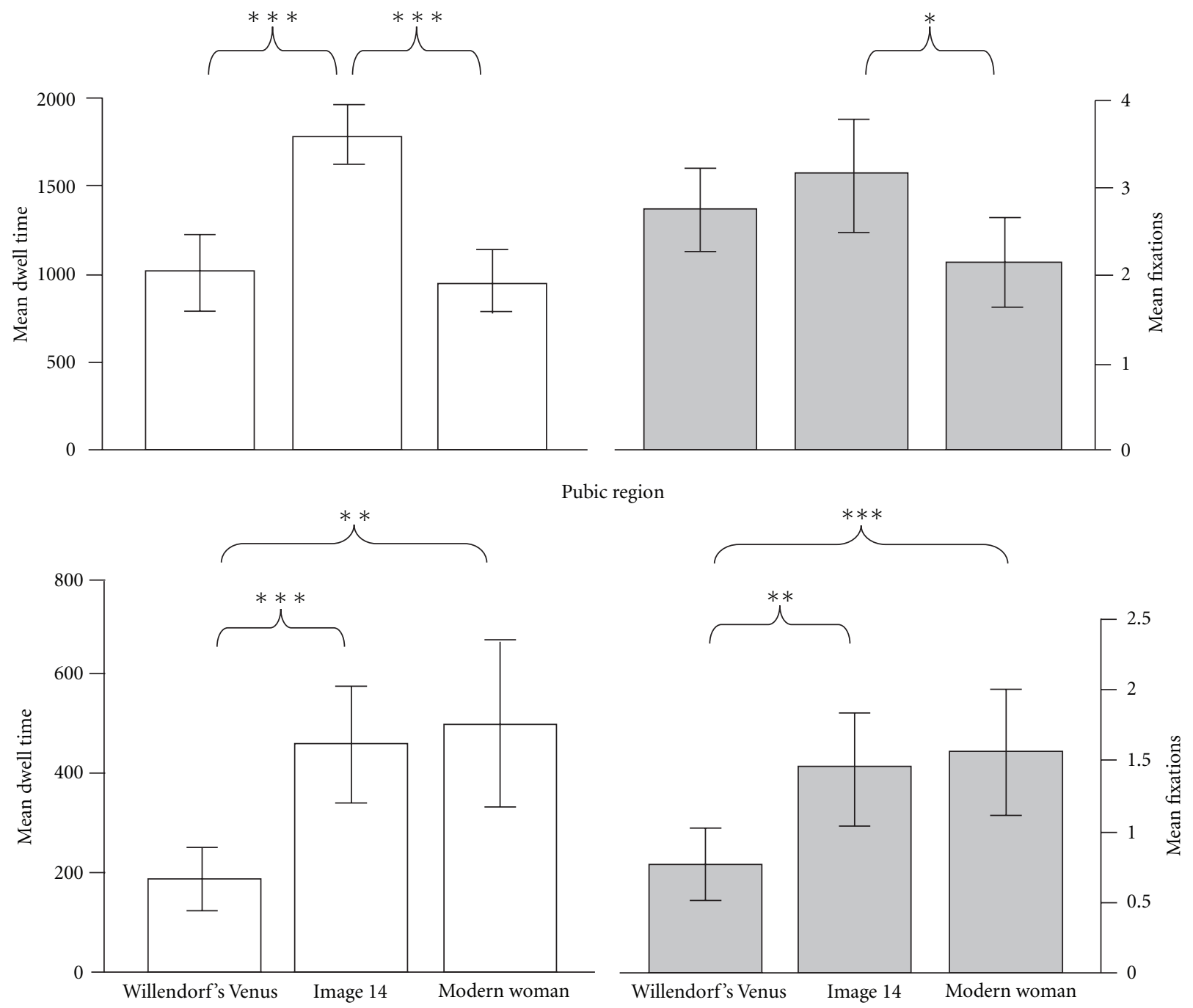

FigURE 5: Eye-tracking data (dwell times (open bars) and numbers of fixations (grey) made by men who viewed the Willendorf Venus, image 14: the so-called "Brassempouy Venus", and a front-posed image of a modern woman. Paired $t$-tests: ${ }^{*} P<.05 ;{ }^{* *} P<.01$; ${ }^{* * *} P<.001$. 
Willendorf Venus (Figure 5). The thighs of the modern image received more fixations, $t(34)=2.21, P<.05$, and longer dwell times, $t(34)=3.17, P<.01$, than the thighs of the Willendorf Venus. Similarly, the thighs of the modern image attracted more fixations, $t(34)=2.42, P<.05$, and longer dwell times, $t(34)=3.55, P<.001$, compared to figurine no. 14. The lower legs of the modern image attracted more attention when compared to the Willendorf Venus (numbers of fixations: $t(34)=4.78, P<.001$, and dwell times: $t(34)=$ 6.49, $P<.001$ ) and figurine no. 14 (numbers of fixations: $t(34)=3.98, P<.001$, and dwell times: $t(34)=5.52, P<$ $.001)$.

\section{Discussion}

Although we cannot be certain why the hunter-gatherers who lived in Europe in Paleolithic times crafted "Venus" figurines, it is possible to collect quantitative data on how modern people perceive these images, in terms of their attractiveness, and whether they might be depictions of women who are pregnant and members of younger or older age groups. This information may provide some additional insights concerning the significance these figurines, which are the earliest known depictions of the human female form.

The great majority of participants in this study interpreted Venus figurines as being representations of either young adult women or middle-aged women in their mature reproductive years. Only one figurine (from Chiozza Di Scandiano, in Italy) received a significant number of choices for the "adolescent" age category. Thus, in our sample of figurines, originating from different areas of Europe, none were interpreted as being in transition between girlhood and reproductive maturity. All were considered to be reproductively mature, but not all were necessarily young women. The more endomorphic body types, with enlarged and pendulous breasts (e.g., the Willendorf, Grimaldi and Savignano Venuses), were most often interpreted as representations of middle-aged women. Only one figurine was thought to represent an old (postmenopausal) woman. This was the Hohle Fels Venus, recently discovered in the Swabian Jura of SW Germany [4] and dated to 35,000 years ago. As well as being older than other Paleolithic figurines discovered in Europe, this Venus is covered with deep scratches and grooves which were placed there intentionally. It has no head; the small projection at the top of the figurine is a ring-shaped aperture. It is thought that this small figurine hung from a strap and may have been worn as a pendant.

Given that both middle-aged and young adult body types are well represented among these figurines, it is interesting that they also include a wide range of body shapes, as reflected by measurements of their waist-to-hip ratios (WHRs). These range from a WHR of 0.63 in the Eleesivitchi Venus (from Russia) to 1.56 in the Lespugue Venus, from the Pyrenees/Aquitaine region of France. In modern human populations, a low feminine WHR is typically correlated with good health and reproductive fitness. Hence, WHRs in the range between 0.67 and 0.8 occur in healthy young women during their reproductive years [15]. Women with narrow waists and large breasts have significantly higher circulating levels of estradiol and progesterone during their menstrual cycles [16] and a greater probability of achieving conception [17]. Cross-cultural studies indicate that feminine WHRs within the range $0.6-0.8$ are rated as most attractive by men belonging to diverse modern populations (Germany: [18], UK: [19], USA: [20], Tanzania: [21], Cameroon: [22], and China: [23]). There have been debates about the relative importance of WHR and body mass index (BMI) in masculine perceptions of female attractiveness [24]. However, recent experiments using images of women who underwent micrograft surgery in order to reduce WHR (but not BMI) have shown that an "hourglass" body shape provides a crucial attractiveness cue [25-27]. Singh [9, 28] has proposed that the female "hourglass" figure provides an honest signal of a healthy feminine fat distribution, and that sexual selection, as well as natural selection, has favored the evolution of this "gynoid" pattern of fat deposition in women. Three of the 14 Paleolithic Venuses included in the present study have WHRs within the modern range for higher attractiveness and health (Eleesivitchi (0.63), Petrkovice (0.72), and the Brassempouy example, no. 14 (0.78). These figurines were rated as being more attractive than most others, although the numerical scores they received were lower than those given to a modern sculpture of a young woman having an hourglass figure (WHR 0.69).

Singh [9] measured the WHRs of 286 ancient sculptures from Greece, India, and Africa, including Egypt. Singh found that, although the WHR measurements of these ancient sculptures varied, the average female WHR in each case was 0.7, as compared to 0.9 for sculptures of males. Hudson and Aoyama's [10] measures of ancient Japanese clay figurines (Jomon figures) also reveal that most have WHRs of around 0.7. We suggest that status of the Paleolithic European Venus figurines must be different, as most of them do not have narrow waists or an "hourglass" body shape. Only 21\% of the images we used had low WHRs. However, most Venus figurines have thick waists and compact body shapes, as typified by the Willendorf, Lespugue, and Dolní Věstonice examples in our study. This also appears to be the case for most of the Venus figurines that are depicted in the archeological literature [1]. Venuses having low WHRs and hourglass figures, such as are consistent with health and attractiveness in modern populations, therefore represent a subset, and a minority, among representations of the female form in the Paleolithic period.

Three of the Venuses in this study were judged by significant numbers of participants to be representations of pregnant women. These figurines originate from geographically widely separated sites, in France (the Laussel Venus), Russia (Kostenki 1. Statuette no. 3) and Italy (the Savignano Venus). Five Venuses were assessed as being representations of nonpregnant women, and the remaining six figurines received similar scores for possible pregnancy or nonpregnancy. The heavy body builds and enlarged breasts of some of these Venuses may have contributed to doubts concerning their intended reproductive status.

The Brassempouy figurine (no. 14) was rated as "nonpregnant" by 86 participants and "pregnant" by 75 others. 
It will be recalled that this figurine, despite its corpulent appearance had a relatively low WHR (0.78) and was ranked no. 6 among the images in terms of its sexual attractiveness. In a separate experiment (involving different participants), this figurine was used to assess men's visual attention using an eye-tracking machine. Interestingly, the midriff of this figurine received significantly more visual fixations, and longer dwell times, than the midriff of either the Willendorf Venus (WHR 1.16) or the image of a modernday woman having a narrow waist (WHR 0.7). It is possible that uncertainties about the reproductive condition depicted by figurine no. 14 might have driven additional attention and focus upon its midriff. However, data referring to this figurine must be treated with some circumspection due to its doubtful status. Thus, it was reconstructed from a number of fragments and is not considered by some authorities to be a true representation of its original, intact condition. White [13] has examined the evidence at first hand and reviewed information concerning the mammoth ivory figurines discovered at Brassempouy. He provides convincing arguments for their authenticity and shows that they have been crafted using similar techniques to those employed at other sites in Europe. Thus, he rejects suggestions that they may have been faked [12]. However, the highly fragmentary nature of many of the Brassempouy figurines has resulted, in the case of figurine no. 14, in the creation of a hybrid which may owe more to artistic license than to archaeological accuracy.

Previous eye-tracking studies have shown that, when men view nude images of women, they direct considerable visual attention to the breasts and midriff $[11,29,30]$, particularly when judging health [29]. In the current study, the greatly enlarged breasts of the Paleolithic figurines received more fixations and longer dwell times than was the case for the modern-day image, and this difference was most pronounced in the case of the Willendorf Venus. The head received much less visual attention than the breasts of all three images. The absence of any facial features in the Willendorf Venus did not affect men's eye-tracking scores, which were not significantly different from those recorded when viewing the Brassempouy figurine, despite the fact that it has a well-defined nose and eye sockets. Men's eye movements during attractiveness judgments of Venus figurines, thus, resemble those that occur when examining images of modern-day women, with the exception that the breasts and midriff of figurines may command more attention. Men generally pay less attention to the lower body than the upper body of female images during eye-tracking sessions $[11,29]$. The same appears to be true for Venus figurines, with the caveat that the pubic area and lower legs of figurines received less fixations and shorter dwell times than those of the modern female image.

The results presented here indicate that Paleolithic Venus figurines, from widely separated parts of Europe, are often rated in similar ways, in terms of their perceived reproductive and age status or attractiveness. Figurines may sometimes have slim waists, but are sometimes more endomorphic in appearance. Some are perceived as representations of pregnant women whereas most are not. The great majority of figurines are considered to be depictions of middle-aged or young adult women. Only a subset conforms to Singh's hypothesis concerning the female "hourglass" figure, as an honest signal of reproductive health and fertility, and its representation in ancient art [9]. These Venus figurines, which have WHRs in the range between 0.6 and 0.8 , received higher ratings for attractiveness. Thus, these types of figurines might be representations of actual women or idealized representations of attractive women. Yet many of the figurines in our study, as in archeological collections covering this time period, have endomorphic body types and much thicker waists, with WHRs greater than 1.0. This is well above the range of WHRs for women in modern populations, who are healthy and in their reproductive years. The breasts and buttocks of Venus figurines are often exaggerated in size. Some are perceived as being pregnant or possibly pregnant, and this might accord with notions that Venus figurines function as symbolic representations of fertile women. Others are not perceived as being pregnant, however, but are rated as being middle aged and of lower attractiveness.

Why were such images of females created in the Paleolithic period, across wide areas of Europe? Some additional insight into this problem may be gained by considering Venus figurines in the broader ecological context of the lives of the hunter-gathers who made them and of climatic conditions in Europe at that time. During the period between 30,000 and 18,000 years ago, there was a major glaciation and a marked deterioration of the climate, which was most pronounced in northern parts of Europe [31]. Anatomically modern humans were widespread in Europe by this period, but population densities were almost certainly low, consisting of scattered groups. In this preagricultural world, human survival depended upon success in hunting and gathering. With the possible exception of the single Hohle Fels figurine, Venus figurines were made during this harsh, glacial climatic period, and they are thought to constitute evidence that a shared cultural tradition existed in Paleolithic Europe $[2,3]$. What role these female images might have played in social contexts, such as bartering or alliance building between hunter-gatherer groups, remains highly speculative $[1,2,31]$. There has also been discussion of these figurines with regard to the occurrence of obesity in the Paleolithic society [5]. Beller [32], for example, commented that "obesity was already a fact of life for Paleolithic man or at least for Paleolithic woman." However, given the extremely challenging climatic conditions which prevailed at this time and the hardships experienced by hunter-gatherers, it seems unlikely that obesity would have been commonplace in Paleolithic societies. Perhaps only a minority of women survived to become multiparous, middle-aged, and corpulent, as depicted by many of the figurines. Images of very well-nourished, mature females might, thus, have been cultural expressions of hoped-for success in the very difficult struggle to survive, as well as to reproduce. Gvozdover [3] has stressed that the female image probably played multiple roles in the European Paleolithic culture. Russell [6] cautions that individual differences in style, among the makers of these figurines and stylistic changes throughout the Paleolithic, may account for some of the variability exhibited by their work. 
We suggest three possible roles for Venus figurines. Firstly, a minority of images may have been intended to represent young, sexually attractive and nulliparous adult females. These might truly be considered as "Venuses" in the conventional sense. Secondly, a subset of figurines represented changes in body shape during pregnancy and might be symbols of fertility. Thirdly, the figurines, depicting corpulent and often middle-aged women, may not have been "Venuses" in any modern or conventional sense. They may, instead, have symbolized the hope for survival and for the attainment of a well-nourished (and thus reproductively successful) maturity, during the harshest period of the major glaciation in Europe.

\section{Acknowledgments}

The authors are grateful to Dr. Gina Grimshaw for assistance with the eye-tracking experiments and to all the participants who volunteered to take part in the studies. They are also grateful to the Editor Dr. Benjamin Campbell and the two anonymous reviewers for providing us with very useful and critical comments, particularly those pertaining to the debates surrounding the Brassempouy figurines. These comments were very helpful in improving our paper.

\section{References}

[1] H. Delporte, L'Image de la Femme dans l'Art Prehistorique, Picard, Paris, France, 1979.

[2] C. Gamble, "Interaction and alliance in palaeolithic society," Man, vol. 17, no. 1, pp. 92-107, 1982.

[3] M. D. Gvozdover, "The typology of female figurines of the Kostenki Paleolithic culture," Soviet Anthropology and Archaeology, vol. 27, pp. 32-94, 1989.

[4] N. J. Conard, "A female figurine from the basal Aurignacian of Hohle Fels Cave in southwestern Germany," Nature, vol. 459, no. 7244, pp. 248-252, 2009.

[5] G. A. Bray, "Historical framework for the development of ideas about obesity," in Handbook of Obesity: Etiology and Pathophysiology, G. A. Bray and C. Bouchard, Eds., pp. 1-31, Marcel Dekker, New York, NY, USA, 2004.

[6] P. Russell, "Learning from curves: the female figurine in Palaeolithic culture," Rock Art Research, vol. 23, pp. 41-49, 2006.

[7] L. McDermott, "Self-representation in Upper Paleolithic female figurines," Current Anthropology, vol. 37, no. 2, pp. 227275, 1996.

[8] P. C. Rice, "Prehistoric venuses: symbols of motherhood or womanhood?" Journal of Anthropological Research, vol. 37, pp. 402-414, 1981.

[9] D. Singh, "Universal allure of the hourglass figure: an evolutionary theory of female physical attractiveness," Clinics in Plastic Surgery, vol. 33, no. 3, pp. 359-370, 2006.

[10] M. J. Hudson and M. Aoyama, "Waist-to-hip ratios of Jomon figurines," Antiquity, vol. 81, no. 314, pp. 961-971, 2007.

[11] B. J. Dixson, G. M. Grimshaw, W. L. Linklater, and A. F. Dixson, "Eye-tracking of men's preferences for waist-to-hip ratio and breast size of women," Archives of Sexual Behavior, vol. 40, pp. 51-58, 2011.

[12] U. Niedhorn, The Lady From Brassempouy: A Fake- a Hoax, Haag and Herchen, Frankfurt, Germany, 1990.
[13] R. White, "The women of brassempouy: a century of research and interpretation," Journal of Archaeological Method and Theory, vol. 13, no. 4, pp. 250-303, 2006.

[14] A. D. Lykins, M. Meana, and G. Kambe, "Detection of differential viewing patterns to erotic and non-erotic stimuli using eye-tracking methodology," Archives of Sexual Behavior, vol. 35, no. 5, pp. 569-575, 2006.

[15] B. Marti, J. Tuomilehto, V. Salomaa, L. Kartovaara, H. J. Korhonen, and P. Pietinen, "Body fat distribution in the Finnish population: environmental determinants and predictive power for cardiovascular risk factor levels," Journal of Epidemiology and Community Health, vol. 45, no. 2, pp. 131-137, 1991.

[16] G. Jasieńska, A. Ziomkiewicz, P. T. Ellison, S. F. Lipson, and I. Thune, "Large breasts and narrow waists indicate high reproductive potential in women," Proceedings of the Royal Society B, vol. 271, no. 1545, pp. 1213-1217, 2004.

[17] S. F. Lipson and P. T. Ellison, "Comparison of salivary steroid profiles in naturally occurring conception and non-conception cycles," Human Reproduction, vol. 11, no. 10, pp. 2090-2096, 1996.

[18] R. Henss, "Waist-to-hip ratio and female attractiveness. Evidence from photographic stimuli and methodological considerations," Personality and Individual Differences, vol. 28, no. 3, pp. 501-513, 2000.

[19] A. Furnham, T. Tan, and C. McManus, "Waist-to-hip ratio and preferences for body shape: a replication and extension," Personality and Individual Differences, vol. 22, no. 4, pp. 539-549, 1997.

[20] D. Singh and R. K. Young, "Body weight, waist-to-hip ratio, breasts, and hips: role in judgments of female attractiveness and desirability for relationships," Ethology and Sociobiology, vol. 16, no. 6, pp. 483-507, 1995.

[21] F. Marlowe, C. Apicella, and D. Reed, "Men's preferences for women's profile waist-to-hip ratio in two societies," Evolution and Human Behavior, vol. 26, no. 6, pp. 458-468, 2005.

[22] B. J. Dixson, A. F. Dixson, B. Morgan, and M. J. Anderson, "Human physique and sexual attractiveness: sexual preferences of men and women in Bakossiland, Cameroon," Archives of Sexual Behavior, vol. 36, no. 3, pp. 369-375, 2007.

[23] B. J. Dixson, A. F. Dixson, B. Li, and M. J. Anderson, "Studies of human physique and sexual attractiveness: sexual preferences of men and women in China," American Journal of Human Biology, vol. 19, no. 1, pp. 88-95, 2007.

[24] M. J. Tovée and P. L. Cornelissen, "The mystery of female beauty," Nature, vol. 399, no. 6733, pp. 215-216, 1999.

[25] D. Singh and P. K. Randall, "Beauty is in the eye of the plastic surgeon: waist-hip ratio (WHR) and women's attractiveness," Personality and Individual Differences, vol. 43, no. 2, pp. 329340, 2007.

[26] D. Singh, B. J. Dixson, T. S. Jessop, B. Morgan, and A. F. Dixson, "Cross-cultural consensus for waist-hip ratio and women's attractiveness," Evolution and Human Behavior, vol. 31, no. 3, pp. 176-181, 2010.

[27] B. J. Dixson, K. Sagata, W. L. Linklater, and A. F. Dixson, "Male preferences for female waist-to-hip ratio and body mass index in the highlands of papua New Guinea," American Journal of Physical Anthropology, vol. 141, no. 4, pp. 620-625, 2010.

[28] D. Singh, "Female mate value at a glance: relationship of waistto-hip ratio to health, fecundity and attractiveness," Neuroendocrinology letters, vol. 23, supplement 4, pp. 81-91, 2002.

[29] P. L. Cornelissen, P. J. B. Hancock, V. Kiviniemi, H. R. George, and M. J. Tovée, "Patterns of eye movements when male and female observers judge female attractiveness, body fat and 
waist-to-hip ratio," Evolution and Human Behavior, vol. 30, no. 6, pp. 417-428, 2009.

[30] B. J. Dixson, G. M. Grimshaw, W. L. Linklater, and A. F. Dixson, "Eye tracking of men's preferences for female breast size and areola pigmentation," Archives of Sexual Behavior, vol. 40, pp. 43-50, 2011.

[31] C. Stringer and C. Gamble, In search of the Neanderthals, Thames and Hudson, New York, NY, USA, 1993.

[32] A. S. Beller, Fat and Thin: A Natural History of Obesity, Farrar, Straus, and Giroux, New York, NY, USA, 1977. 


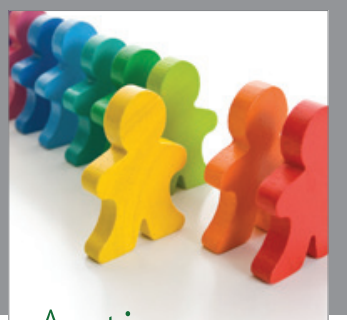

Autism

Research and Treatment
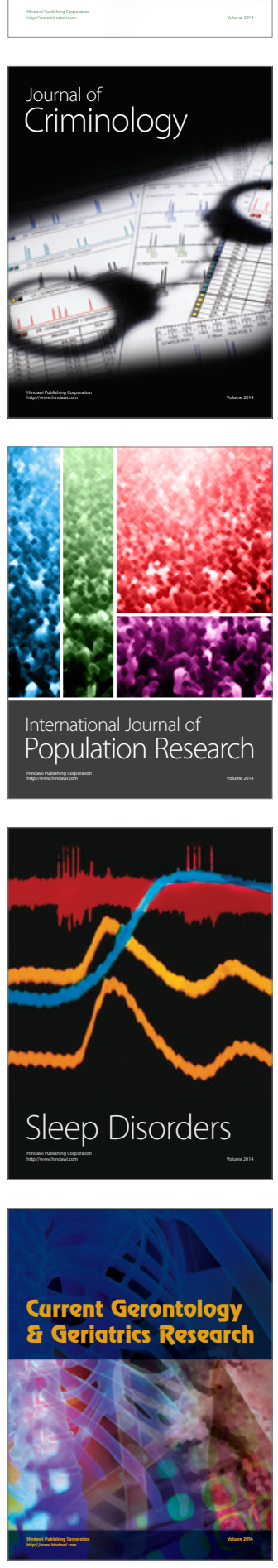
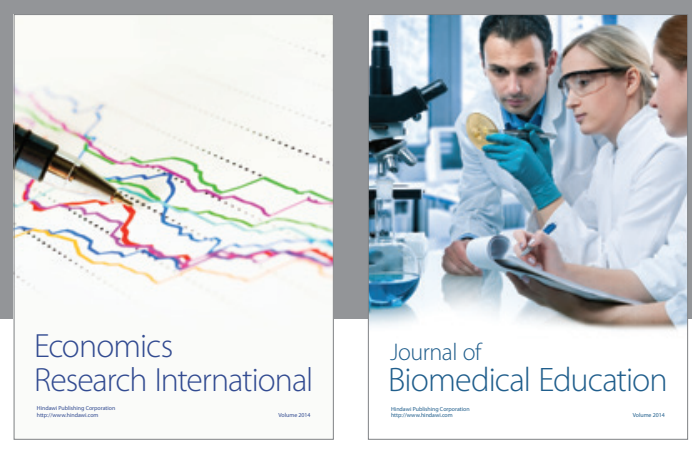

Journal of

Biomedical Education

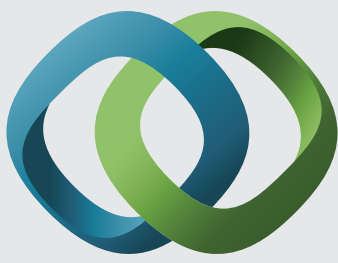

\section{Hindawi}

Submit your manuscripts at

http://www.hindawi.com
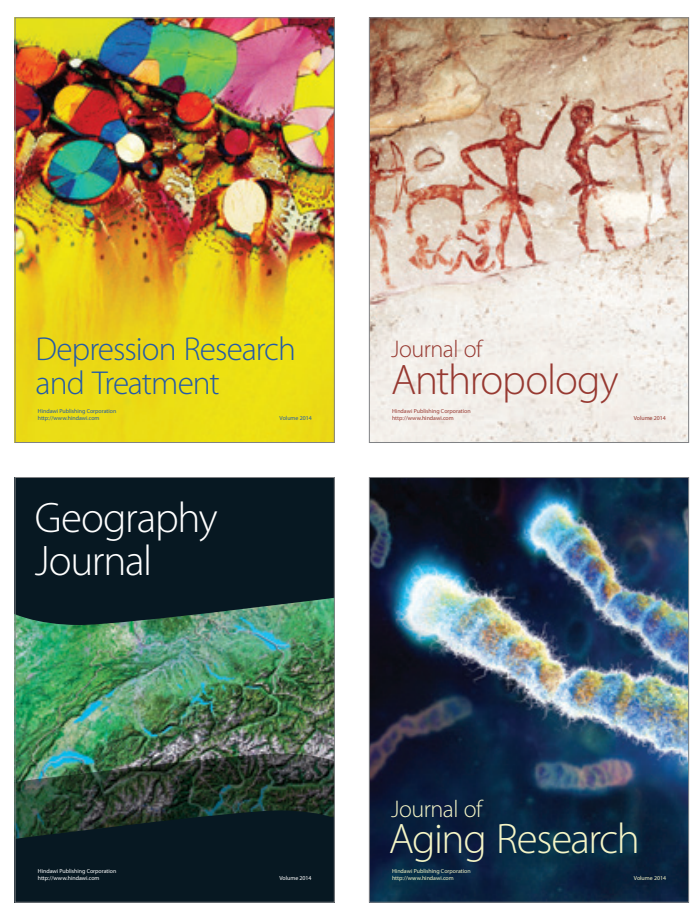

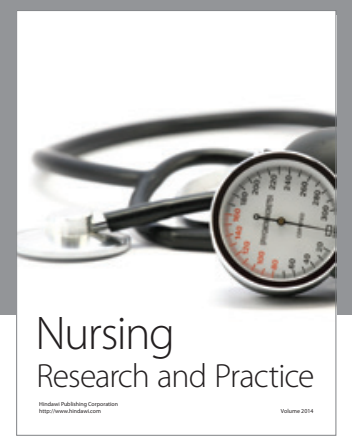

Nursing

Research and Practice

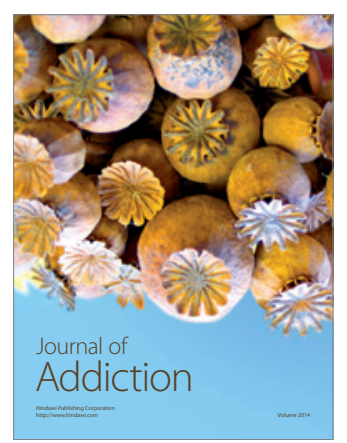

Child Development

Research

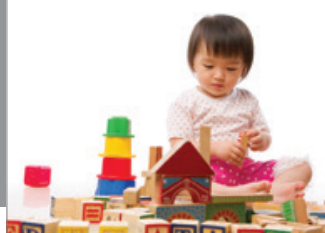

迥
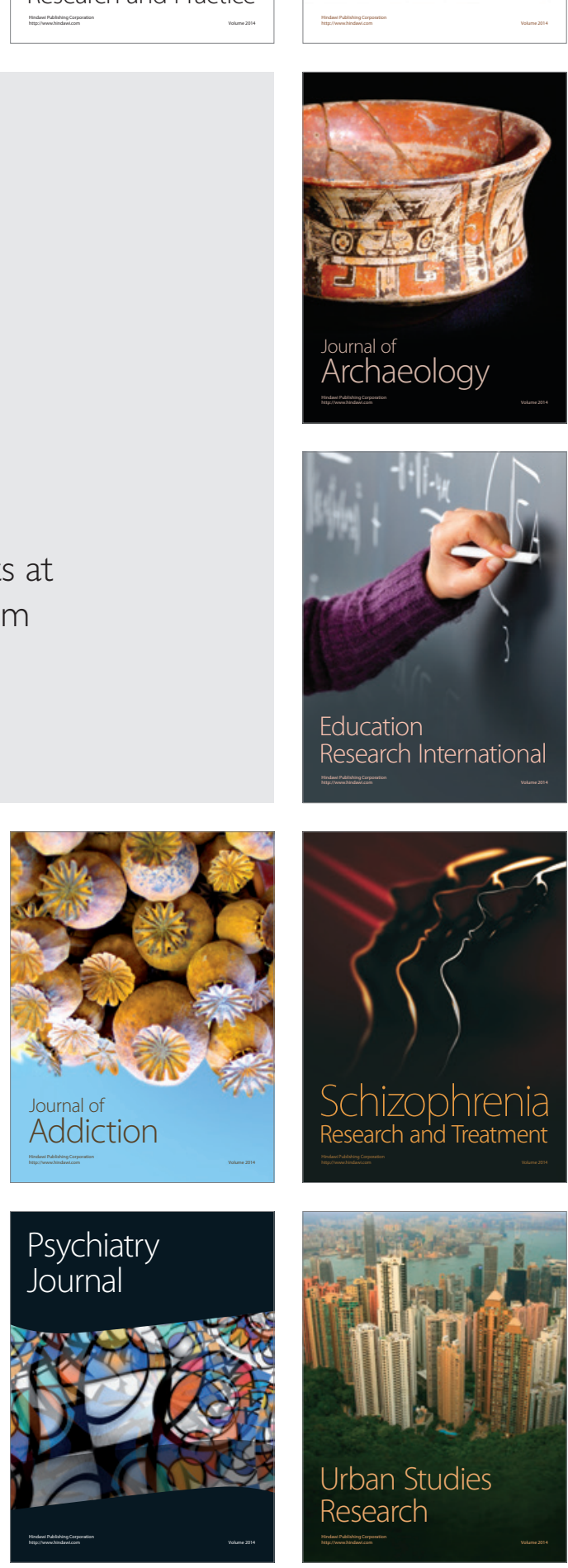